Case Report

\title{
A New Case of $\operatorname{dic}(1 ; 15)(p 11 ; p 11)$ in AML M1: Apropos of a Case and a Review of the Literature
}

\author{
Deniz Gören Şahin, ${ }^{1}$ Beyhan Durak, ${ }^{2}$ Eren Gündüz, ${ }^{1}$ \\ Sevilhan Artan, ${ }^{2}$ and Olga Meltem Akay ${ }^{1}$ \\ ${ }^{1}$ Department of Hematology, School of Medicine, Eskisehir Osmangazi University, 26480 Eskisehir, Turkey \\ ${ }^{2}$ Department of Medical Genetics, School of Medicine, Eskisehir Osmangazi University, 26480 Eskisehir, Turkey
}

Correspondence should be addressed to Beyhan Durak; beyhand@yahoo.com

Received 15 January 2013; Accepted 4 February 2013

Academic Editors: P. D. Cotter and K. Riemann

Copyright (C) 2013 Deniz Gören Şahin et al. This is an open access article distributed under the Creative Commons Attribution License, which permits unrestricted use, distribution, and reproduction in any medium, provided the original work is properly cited.

Acute myelogenous leukemia (AML) develops as the consequence of a series of genetic changes in a hematopoietic precursor cell. Specific cytogenetic abnormalities have been identified by karyotype analysis in AML. One of the rare chromosomal abnormalities is a dicentric chromosome, which is defined as an aberrant chromosome having two centromeres. In the literature, a limited number of cases have been reported with dic $(1 ; 15)$ in myeloid disorders, but only one case has been reported with in acute megakaryoblastic leukemia. Herein, we report a case of acute myelogenous leukemia without maturation with a $\operatorname{dic}(1 ; 15)($ p11;p11), resulting in trisomy of the long arm of chromosome 1 . To date, this is the second case of $\operatorname{dic}(1 ; 15)$ in acute myelogenous leukemia and the first case in acute myeloblastic leukemia without maturation.

\section{Introduction}

Acute myelogenous leukemia is a progressive malignant disease, which is the result of a sequence of somatic mutations in a multipotent primitive hematopoietic cell [1]. Several risk factors and structural chromosomal abnormalities like deletions, duplications, and translocations have been identified, but the specific cause is still not clear. A rare type of translocation, which is called dicentric chromosome (dic), results from the abnormal fusion of two chromosome pieces, each of which includes a centromere with alpha satellite DNA from both chromosomes. There are a limited number of cases in the literature showing $\operatorname{dic}(1 ; 15)$ in myeloid disorders [2]. To the best of our knowledge, herein we report the second case of dicentric chromosome involving chromosomes 1 and 15 with the karyotype determined as $47, \mathrm{XX},+1, \operatorname{dic}(1 ; 15)(\mathrm{p} 11 ; \mathrm{p} 11),+8$ in acute myelogenous leukemia. Also this is the first case of $\operatorname{dic}(1 ; 15)$ in acute myeloblastic leukemia without maturation.

\section{Case Report}

A 56-year-old woman admitted to our hospital with fatigue and tinnitus. The full blood count showed a pancytopenia with a hemoglobin level of $8.3 \mathrm{~g} / \mathrm{dL}$, a white blood cell count of $1.1 \times 10^{3} / \mu \mathrm{L}$, and a platelet count of $37 \times 10^{3} / \mu \mathrm{L}$. There was no significant abnormality in the biochemical values except slightly elevated lactate dehydrogenase level of $714 \mathrm{U} / \mathrm{L}$. Coagulation tests were normal. Peripheral blood smear was compatible with the blood count. A bone marrow examination showed $75 \%$ of myeloblastic infiltration. Flow cytometric analyses revealed 93.8\% CD34 positivity, $82.8 \%$ CD33 positivity, 90.7\% HLA-DR positivity, and 30.7\% myeloperoxidase positivity in the blastic cell population. CD13, CD14, CD56, and CD64 were negative. A diagnosis of acute myeloblastic leukemia without maturation was made, and remission induction chemotherapy with the $7+$ 3 regimen, cytosine arabinoside $\left(200 \mathrm{mg} / \mathrm{m}^{2}\right.$ in a 24 -hour infusion for 7 days) and idarubicin $\left(12 \mathrm{mg} / \mathrm{m}^{2}\right.$ intravenously 


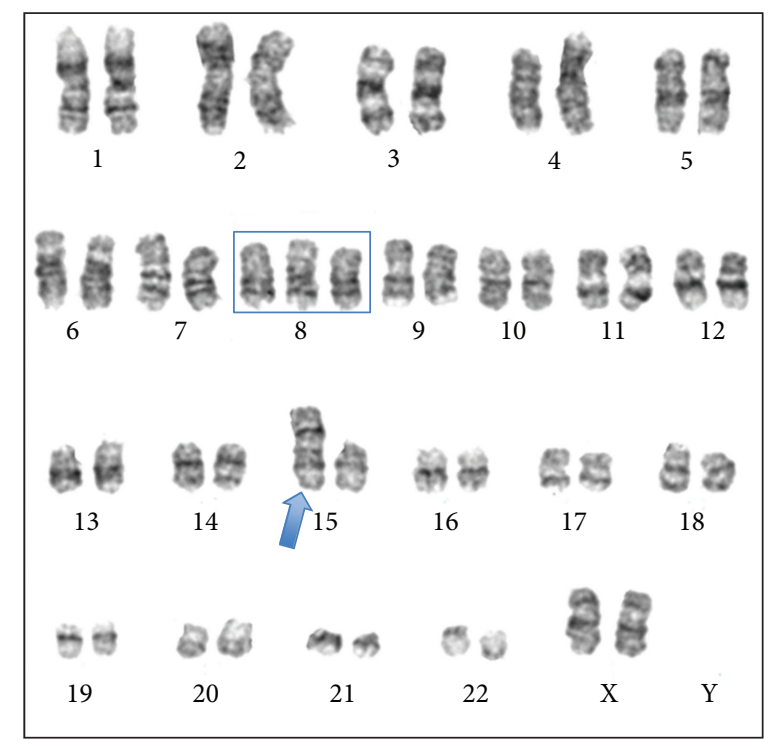

FIGURE 1: Conventional cytogenetic analysis of bone marrow aspirate sample showed the presence of 47,XX,+1,dic(1;15)(p11;p11),+8.

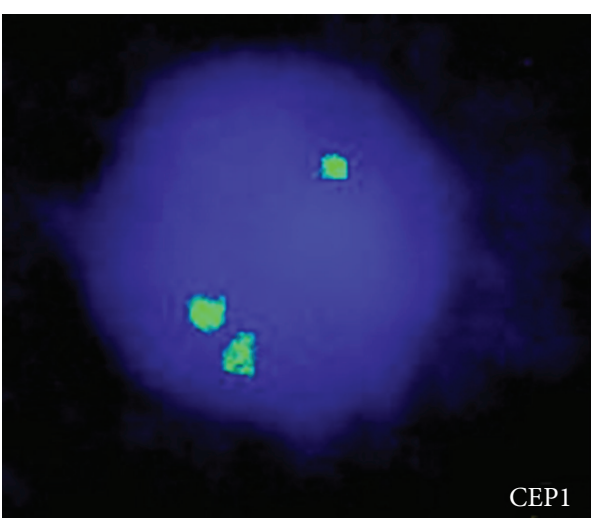

(a)

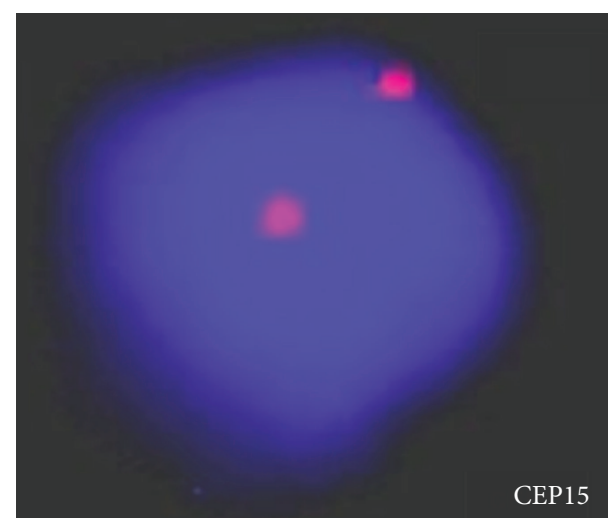

(b)

Figure 2: (a) Trisignal for chromosome 1 centromere. (b) Two signals for chromosome 15 centromere.

for 3 days) was started. Conventional cytogenetic analysis of bone marrow aspirate sample showed the presence of 47,XX,+1,dic(1;15)(p11;p11),+8[20]/46,XX [4] (Figure 1). Fluorescent in situ hybridization for centromere specific probes showed a centromere with alpha satellite DNA from both chromosomes (Figure 2$)$. $t(8 ; 21)$ was considered negative because there was no fusion signal with LSI AML1/ETO Dual Color Dual Fusion Translocation Probe. On the other hand, three ETO (8q21.3) signals confirmed trisomy 8 that was found with cytogenetic analyses. A repeat bone marrow aspiration at 4 weeks after the initiation of induction therapy revealed partial remission. She was then hospitalized for high dose cytosine arabinoside $\left(3 \mathrm{~g} / \mathrm{m}^{2}\right.$ every 12 hour for 5 days) chemotherapy; however, the patient died of sepsis and multiple organ failure on the 21st day of hospitalization.

\section{Discussion}

Acute myelogenous leukemia (AML) results from a series of somatic mutations and/or chromosomal translocations in the majority of cases $[3,4]$. Deletions of all parts of a chromosome (e.g., chromosome 5, 7, or 9) and additional chromosomes (such as trisomy 4, 8, or 13) are also common cytogenetic abnormalities in AML [5]. Besides these common cytogenetic abnormalities, there are some rare variants of translocations such as dicentric chromosomes [2]. In human leukemia, recurrent and clonal dicentric chromosomes have been found to be associated with some subtypes of leukemia, such as $\operatorname{dic}(5 ; 17)$ and $\operatorname{dic}(17 ; 18)$ in myeloid cell proliferations, and $\operatorname{dic}(7 ; 9), \operatorname{dic}(9 ; 12)$ and $\operatorname{dic}(9 ; 20)$ in acute lymphoblastic leukemias [6]. We report a case of acute myeloblastic leukemia with a $\operatorname{dic}(1 ; 15)(\mathrm{p} 11 ; \mathrm{p} 11)$, resulting in trisomy of the long arm of chromosome 1 . Trisomy 8 was 
an additional accompanied chromosomal abnormality in our case. A review of the literature showed only one case with $\operatorname{dic}(1 ; 15)($ p11;p11) in acute myeloid leukemia [7]. Dastugue et al. [7] reported a 25-year-old male who was diagnosed with acute megakaryoblastic leukemia (AML M7). He had had $\operatorname{dic}(1 ; 15)$ and several cytogenetic abnormalities including trisomy 8 , like in our case. In their study, the authors hypothesized that a number of cases of AML M7 may have arisen from a previously undiagnosed myelodysplastic phase. This theory was supported by the high incidence of complex karyotypes, unbalanced changes, and some other chromosomal abnormalities including $\operatorname{dic}(1 ; 15)$ in their study population. There are 9 remaining cases with $\operatorname{dic}(1 ; 15)$ (p11;p11) published in the literature [8-13]. Three out of these 9 cases were myeloproliferative diseases (MPD) (polycythemia vera (PV) in all 3 cases) $[12,13]$ and 6 out of 9 cases were myelodysplastic syndromes (MDS) (mainly refractory anemia (RA): 5 cases; RARS in one case) [8-11].

To the best of our knowledge, this is the first case with dicentric chromosome involving chromosomes 1 and 15 with the karyotype determined as $47, \mathrm{XX},+1, \operatorname{dic}(1 ; 15)(\mathrm{p} 11 ; \mathrm{p} 11),+8$ in acute myeloblastic leukemia without maturation in the literature. Genes involved in $\operatorname{dic}(1 ; 15)$ are unknown. However, the translocation breakpoints are likely to be in heterochromatic regions. Heterochromatin could have roles in centromere architecture and the prevention of merotely, but the possible consequences of heterochromatin rearrangements are still a question mark [6]. Heterochromatin rearrangements (partial trisomies and monosomies) cause imbalance by silencing genes placed in the region of chromosomal breakpoints due to the translocation of heterochromatin to ectopic location [14]. They also instigate functional changes of genes and proteins coupled with heterochromatin. Therefore, further studies are needed to evaluate the role of heterochromatin rearrangements in leukemia etiopathogenesis.

Considering additional cytogenetic abnormality trisomy 8 in our case, we could speculate that one of the pathogenetically important consequences might be gene dosage. The leukemogenic potential of $\operatorname{dic}(1 ; 15)$ may well be ascribed to altered gene dosages resulting from trisomy $1 \mathrm{q}$ and/or trisomy 8 and well-known chromosomal abnormalities found in AML $(+8)$ as well as many solid cancers $(+1 q)$, although the critical gene targets for these chromosomal changes remain to be unveiled.

In conclusion, this is the first case of $\operatorname{dic}(1 ; 15)$ in acute myeloblastic leukemia without maturation. Molecular studies could help elucidate the pathogenetic role of this dicentric chromosome in leukemia.

\section{References}

[1] J. L. Liesveld and M. A. Lichtman, "Acute mylogenous leukemia," in Williams Hematology, K. Kaushansky, M. A. Lichtman, E. Beutler, T. J. Kipps, U. Seligsohn, and J. T. Prchal, Eds., pp. 1277-1399, McGraw-Hill, 2010.

[2] M. K. Andersen and J. Pedersen-Bjergaard, "Increased frequency of dicentric chromosomes in therapy-related MDS and AML compared to de novo disease is significantly related to previous treatment with alkylating agents and suggests a specific susceptibility to chromosome breakage at the centromere," Leukemia, vol. 14, no. 1, pp. 105-111, 2000.

[3] L. Coulombel, D. K. Kalousek, and C. J. Eaves, "Long-term marrow culture reveals chromosomally normal hematopoietic progenitor cells in patients with Philadelphia chromosomepositive chronic myelogenous leukemia," The New England Journal of Medicine, vol. 308, no. 25, pp. 1493-1498, 1983.

[4] C. M. Verfaillie, R. Bhatia, W. Miller et al., "BCR/ABLnegative primitive progenitors suitable for transplantation can be selected from the marrow of most early-chronic phase but not accelerated-phase chronic myelogenous leukemia patients," Blood, vol. 87, no. 11, pp. 4770-4779, 1996.

[5] K. Mrózek and C. D. Bloomfield, "Clinical significance of the most common chromosome translocations in adult acute myeloid leukemia," Journal of the National Cancer Institute Monographs, no. 39, pp. 52-57, 2008.

[6] R. Berger, "Centromeric, pericentromeric and heterochromatin abnormalities in chromasomal rearrangement of human leukemia," Genetics and Molecular Biology, vol. 23, no. 4, pp. 1115-1116, 2000.

[7] N. Dastugue, M. Lafage-Pochitaloff, M. P. Pages et al., "Cytogenetic profile of childhood and adult megakaryoblastic leukemia (M7): a study of the Groupe Fraņais de Cytogénétique Hématologique (GFCH)," Blood, vol. 100, no. 2, pp. 618-626, 2002.

[8] M. Jotterand-Bellomo, V. Parlier, P. M. Schmidt, and P. Beris, "Cytogenetic analysis of 54 cases of myelodysplastic syndrome," Cancer Genetics and Cytogenetics, vol. 46, no. 2, pp. 157-172, 1990.

[9] J. T. Mascarello, C. Osborn, and R. P. Kadota, "A dysmorphic child with myelodysplasia characterized by a duplication of $1 \mathrm{q}$ and multiple duplications of 3q," Cancer Genetics and Cytogenetics, vol. 38, no. 1, pp. 9-12, 1989.

[10] C. Mecucci, G. Tricot, M. Boogaerts, and H. Van den Berghe, "An identical translocation between chromosome 1 and 15 in two patients with myelodysplastic syndromes," British Journal of Haematology, vol. 62, no. 3, pp. 439-445, 1986.

[11] L. Michaux, J. Dierlamm, C. Mecucci et al., "Dicentric (1;15) in myeloid disorders," Cancer Genetics and Cytogenetics, vol. 88, no. 1, pp. 86-89, 1996.

[12] B. Swolin, A. Weinfeld, and J. Westin, "Trisomy 1q in polycythemia vera and its relation to disease transition," American Journal of Hematology, vol. 22, no. 2, pp. 155-167, 1986.

[13] D. Wurster Hill, J. Whang Peng, and O. R. McIntyre, "Cytogenetic studies in polycythemia vera," Seminars in Hematology, vol. 13, no. 1, pp. 13-32, 1976.

[14] A. L. Pidoux and R. C. Allshire, "The role of heterochromatin in centromere function," Philosophical Transactions of the Royal Society B, vol. 360, no. 1455, pp. 569-579, 2005. 


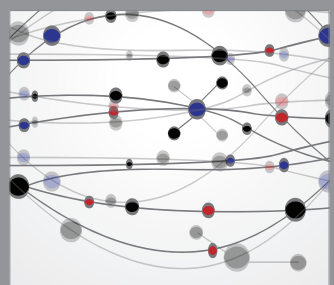

The Scientific World Journal
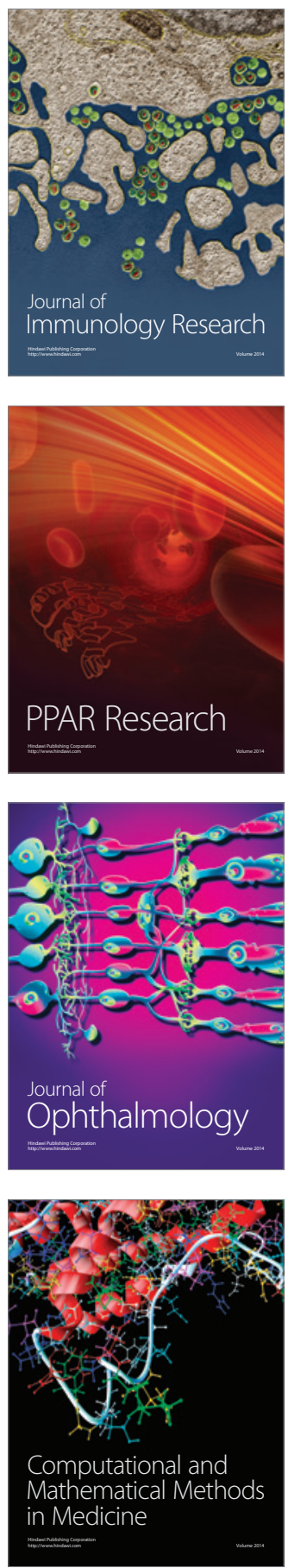

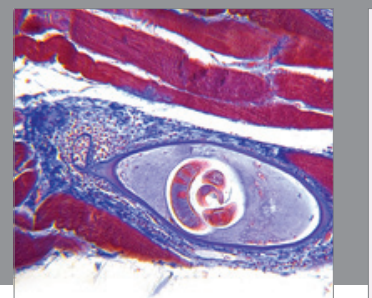

Gastroenterology

Research and Practice
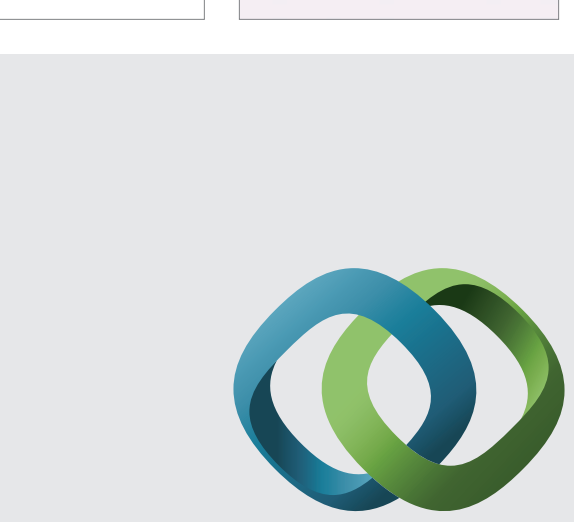

\section{Hindawi}

Submit your manuscripts at

http://www.hindawi.com
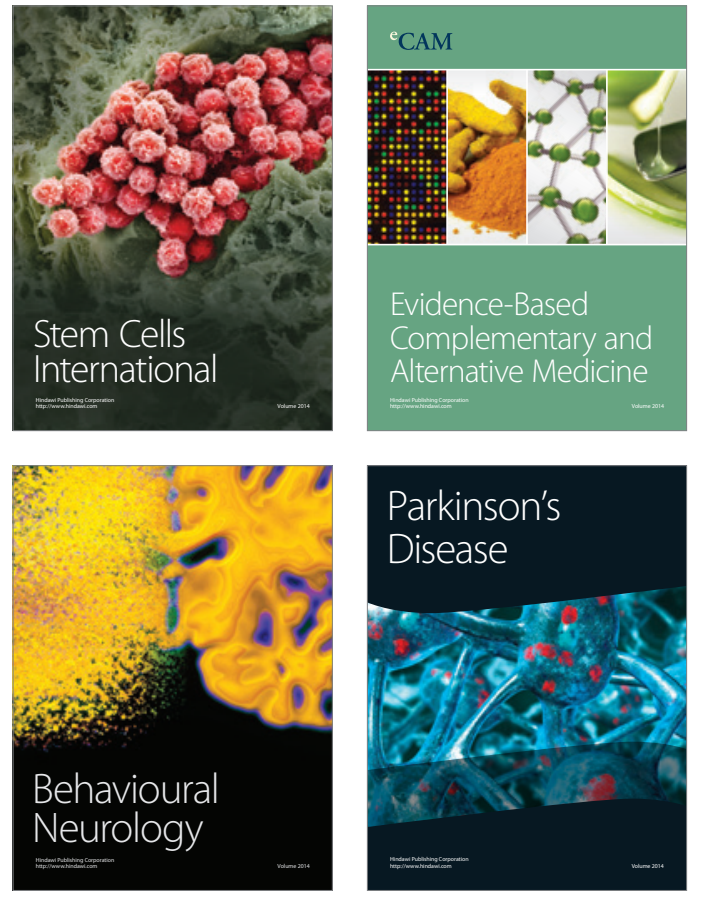
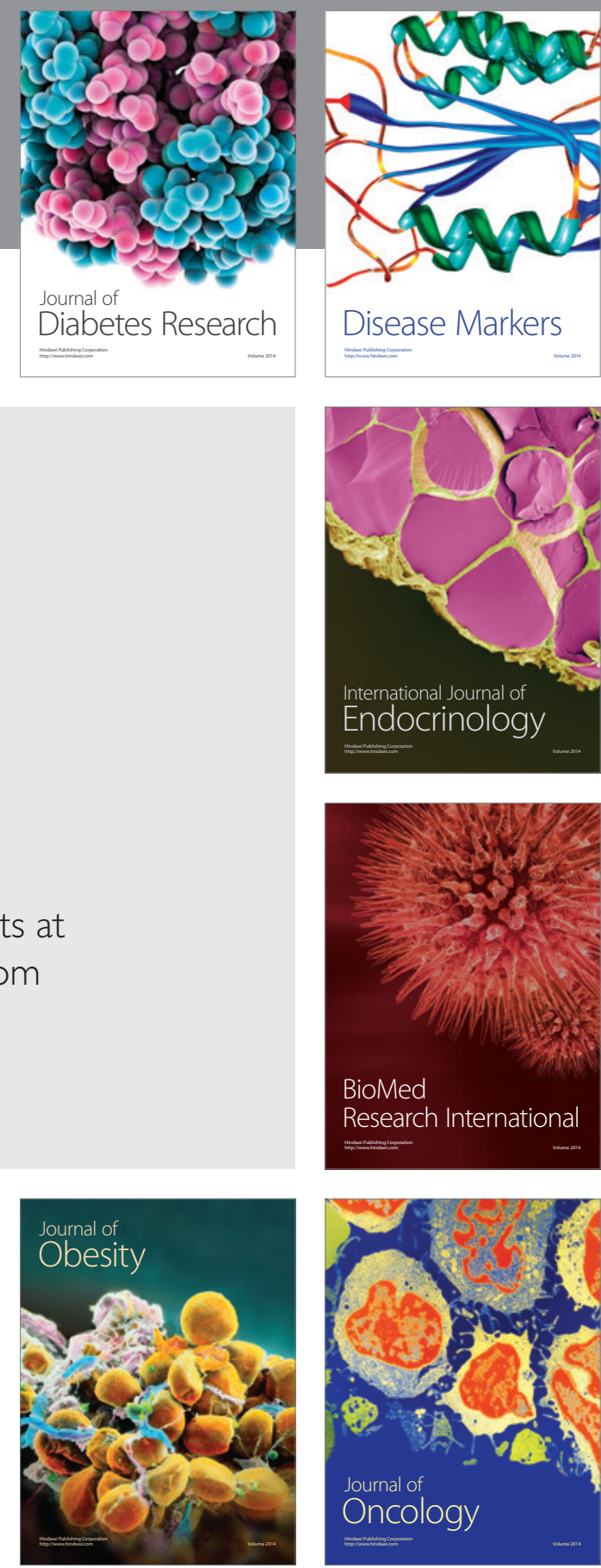

Disease Markers
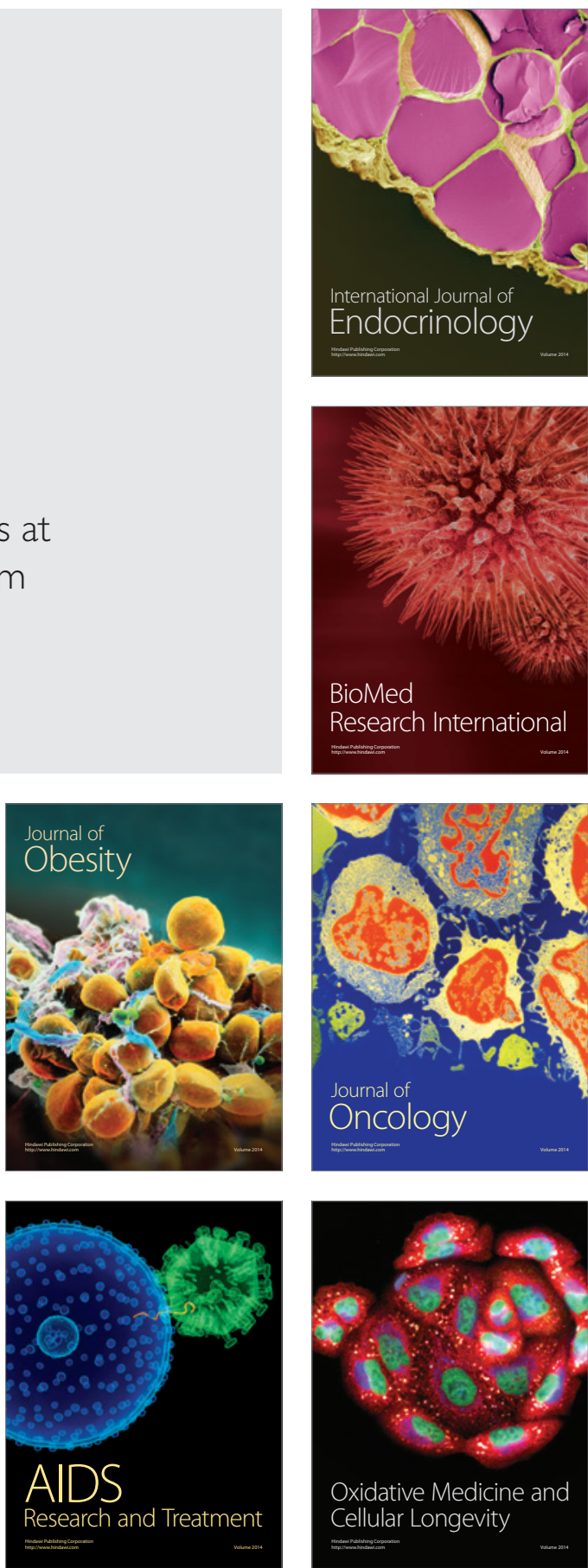